\title{
Parâmetros de projeto de microrreservatório, de PAVIMENTOS PERMEÁVEIS E DE PREVISÃO DE ENCHENTES URBANAS
}

\section{DESIGN PARAMETERS FOR MICRO RESERVOIR, FOR POROUS PAVEMENTS AND FOR FORECAST OF URBAN FLOW}

\author{
LOURENÇO LEME DA COSTA JUNIOR \\ Msc. Engenharia Urbana/ PPGEU/Ufscar. Assessor Técnico

\begin{abstract}
ADEMIR PACELI BARBASSA
Doutor em Engenharia Hidráulica e Saneamento. Professor DECiv/PPGEU/UFSCar - Programa de Pós-Graduação em Engenharia Urbana
\end{abstract}

Recebido: 29/03/05 Aceito: 27/01/06

\section{RESUMO}

Esta pesquisa teve como objetivo principal avaliar o uso e a ocupação dos lotes de uma área urbana e analisar as possibilidades de uso das medidas de controle local de inundação: microrreservatórios de detenção e pavimentos permeáveis. A área de estudo foi a Sub-bacia Hidrográfica Urbana da Ponte Seca (SBHUPS), em Jaboticabal - SP. O total de lotes da SBHUPS é 1.777. Avaliaram-se 164 lotes, por amostragem aleatória estratificada proporcional de acordo com a área. Utilizou-se de levantamento de campo, informaçôes cadastrais e entrevistas com moradores para a coleta dos dados. Caracterizaram-se a área livre, área impermeabilizada, área construída, taxa de ocupação (TO), taxa de ocupação e impermeabilização (TOI), tipo de solo, nível do lençol freático e topografia de cada lote amostrado. Argüiramse os moradores sobre a aceitação do uso das medidas. Estes parâmetros foram usados para avaliar as possibilidades de suas implantações e, então, avaliaram-se os custos. Os valores médios por estrato indicam que a TO e a TOI decrescem com o aumento da área do lote. Obtiveram-se relações entre TO e área do lote, TOI e área do lote e TO e TOI representadas por equaçōes, cujos coeficientes de determinação ficaram acima de 0,96 . O uso dos microrreservatórios de detenção, como medida de controle, foi limitado pela aceitação dos moradores, a $82,8 \%$ dos lotes. O uso do pavimento permeável foi restringido pelos parâmetros área livre e aceitação dos moradores.

PALAVRAS-CHAVE: Impermeabilização, drenagem urbana, taxa de ocupação e impermeabilização, bacia hidrográfica, planejamento urbano.

\begin{abstract}
This report had the main objective to evaluate the use and the occupation of the plot from an urban hydrographic basin and to analyze the possibilities at the use of measures of local control offloods, such as micro reservoir of detention and porous pavements. The area studied was the urban hydrographic basin from "Ponte Seca" (SBHUPS), on Jaboticabal City, São Paulo. The total of plots on BHUPS is 1.777. During the research it was analyzed 164 plots, using proportional random sampling. The sample was divided in: plots smaller than $160 \mathrm{~m}^{2}$, between $160 \mathrm{~m}^{2}$ and $300 \mathrm{~m}^{2}$, between $300 \mathrm{~m}^{2}$ and $600 \mathrm{~m}^{2}$, between $600 \mathrm{~m}^{2}$ and $900 \mathrm{~m}^{2}$, between $900 \mathrm{~m}^{2}$ and $1500 \mathrm{~m}^{2}$ and bigger than $1500 \mathrm{~m}^{2}$. The data was collected on survey "in loco", registered information and also interview with the residents. For lots characterization, free area, impermeability area, built area, occupation rate, occupation and impermeability rate, soil type, water table level, topografic were used. The residents were questioned about the acceptation of the use of these measures. This parameters were utilized to evaluated the possibilities to introduce it, and then, the costs were evaluate. The results showed that TO goes down with the increasing of the plots' area. The TOI showed the same behavior. Were obtained relation between TO and area of plot, TOI and area of plot and TO and TOI represented by equations, whose the coefficient of determination got higher than 0,96. The use of micro reservoir of detention, as a control measure, was limited by the acceptation from the residents to $82,8 \%$ of the plots. The use of permeable floor was limited by the free area parameter and the acceptation from the residents.
\end{abstract}

KEYWORDS: Impermeable, urban drainage, impermeable occupation rate, basin, urban planning.

\section{INTRODUÇÃO}

O processo de ocupação dos centros urbanos provoca impactos no meio ambiente, particularmente, relacionados com as modificações do ciclo hidrológico e a intensa impermeabilização do solo, cujas consequiências são o crescimento dos eventos de inundações urbanas em número e magnitude com prejuízos materiais, patrimoniais e humanos para a sociedade.

O planejamento da drenagem, instrumento de gerenciamento e ferramen- ta de tomada de decisão de administradores, objetiva a redução da aplicação de recursos financeiros necessários para a correção dos prejuízos e dos impactos sociais decorrentes da ausência dessa prática. Atualmente, podem-se utilizar medidas de controle das inundaçôes no lote e me- 
didas convencionais na bacia. Mas, para planejar a adoção destas medidas de forma realista, é necessária a caracterização metódica e criteriosa da bacia hidrográfica.

Objetiva-se com este trabalho avaliar a ocupação e a impermeabilização dos lotes, visando ao controle de inundação no lote sob dois aspectos: avaliar o atendimento das exigências de projeto das medidas de controle local e obter parâmetros hidrológicos que possibilitem a previsão segura de vazões. Para isto os lotes foram caracterizados, obtendo-se a Taxa de Ocupação (TO), Taxa de Ocupação e Impermeabilização (TOI), área dos lotes, área construída e, com isso, analisar as possibilidades de aplicação de medidas de controle no lote.

Escolheram-se para aplicação do estudo as sub-bacias hidrográficas urbanas na região do bairro da Ponte Seca (SBHUPS), em Jaboticabal - SP. Optouse por utilizar o microrreservatório de detenção e o pavimento permeável, como medidas de controle local, pela existência de pesquisas experimentais, simulações com o uso de modelagem e casos.

\section{Microrreservatório de detenção}

O microrreservatório de detenção (MRD) é construído abaixo do nível do solo de edificaçôes para armazenamento temporário de água de chuva. Estes dispositivos têm como funções principais: controle distribuído do escoamento das águas pluviais na bacia hidrográfica, minimização dos efeitos da impermeabilização do solo, recuperação da capacidade de amortecimento da bacia, entre outras.

Em simulações sobre o uso de microrreservatório em lotes de $300 \mathrm{~m}^{2} \mathrm{a}$ $600 \mathrm{~m}^{2}$, com períodos de retorno (TR) de 2 a 5 anos, onde os volumes escoados eram de 39\% a 109\% superiores aos de condições de pré-urbanização, Cruz (1998), com a utilização de microrreservatório de $2,5 \mathrm{~m}^{3}$ e com ocupação de $1 \%$ da área total do lote, obteve resultados em volumes iguais aos de pré-urbanização. Onde, por exemplo, em condiçóes de impermeabilização de $100 \%$ e TR de 5 anos, com lotes de $300 \mathrm{~m}^{2}$, se obteve um volume de detenção de $1,25 \mathrm{~m}^{3}$ e para lote com $600 \mathrm{~m}^{2}$, o volume foi de 2,20 $\mathrm{m}^{3}$. A Figura 1 apresenta um modelo de microrreservatório de detenção.

Pilar e Biain (2000) apud Agra (2001), em simulaçôes do uso de micror-

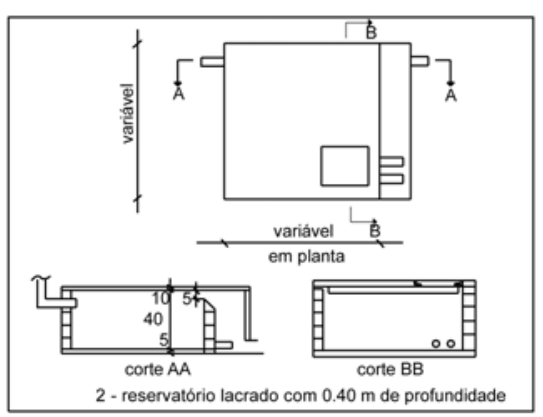

Fonte: Cruz (1998)

\section{Figura I-Modelo de reservatório subterrâneo de 0,40 metro de profundidade lacrado}

reservatórios em lotes com área de $500 \mathrm{~m}^{2}$, declividade de $1 \%$ e $100 \%$ impermeabilizado, obtiveram reduções das vazôes de pico de $25 \%$ a $63 \%$, sendo que os microrreservatórios ocuparam uma área de $2 \%$ a $4 \%$ da área total do lote.

Agra (2001), em análises experimentais de um dispositivo de detenção com $1,0 \mathrm{~m}^{3}$ que armazenava o volume proveniente de um telhado de duas águas com área de $337,5 \mathrm{~m}^{2}(22,5 \times 15 \mathrm{~m})$, instalado no IPH (Instituto de Pesquisas Hidráulicas/UFRGS), obteve reduçôes de pico das vazões de $7 \%$ a $50 \%$ para TR de 5 anos, de acordo com a variabilidade das precipitações, sendo que o descarregador de fundo de pequeno diâmetro apresentou obstruçôes por folhas depositadas no orifício, ocasionando o extravasamento do microrreservatório.

Em simulações sobre a redução de vazões com o uso desse dispositivo, em lotes de $300 \mathrm{~m}^{2}$ e $600 \mathrm{~m}^{2}$ e seus impactos em bacias urbanas, Tassi (2002) obteve, para precipitaçóes com TR de 5 nos, reduçôes de $50 \%$ nas vazões de pico de saída da bacia em relação às vazões de pico sem controle, e para chuvas com TR de 10 anos, a redução foi de $45 \%$.

Dessa forma, o microrreservatório tem apresentado um desempenho significativo, pois pode reduzir em até 50\% ou mais as vazões de pico de saída de lotes, para precipitaçóes com TR de 5 anos e volumes de detenção entre 1,0 e 2,0 $\mathrm{m}^{3}$, sendo recomendado para o combate às inundaçōes urbanas em conjunção com outras medidas estruturais e não-estruturais.

\section{Pavimentos permeáveis}

Os pavimentos permeáveis são superfícies porosas ou perfuradas que permitem a infiltração de parte do escoamento superficial, para dentro de uma cama- da de reservação situada sob o terreno, formada por pedras de granulometria diferenciada, que será absorvida pelo solo, a qual deve ser adequadamente protegida contra colmatação.

Os pavimentos permeáveis, segundo Araújo (1999), são classificados em três tipos: pavimento de asfalto poroso, de concreto poroso e de blocos de concreto perfurado preenchido com areia ou grama. Os pavimentos porosos têm a camada de revestimento executada de forma similar aos pavimentos convencionais, mas com a retirada da fração de areia fina da mistura dos agregados do pavimento. A Figura 2 apresenta um modelo desse dispositivo.

As suas principais aplicações podem ser em: áreas de aeroporto com pequena movimentação de veículos, estacionamentos e calçadas residenciais, pistas e estradas em manutenção, dentre outras. A sua eficiência na redução do escoamento superficial depende, diretamente, de cuidados na manutenção que evite a colmatação do solo, segundo Tassi (2002).

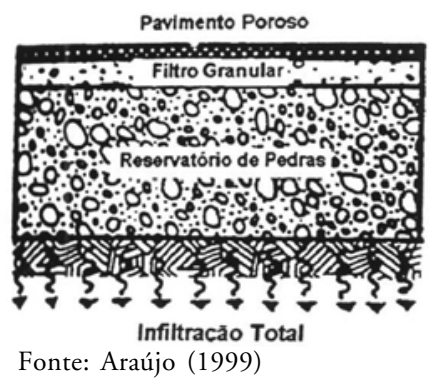

Figura 2 - Pavimento permeável - sistema de infiltração total

As restriçôes para o uso de pavimentos permeáveis são: alto nível da camada impermeável do solo, baixa permeabilidade do solo e lençol freático com o nível elevado. Nestas situações, este dispositivo poderá ser usado como reservatório de detenção, devendo-se prever a instalação de uma superfície impermeável entre o solo e o reservatório de pedras e um sistema de drenagem com tubos perfurados, segundo Araújo (1999).

Com base em estudos experimentais realizados por Araújo (1999), foi comparada hidrologicamente a utilização de pavimentos de diferentes permeabilidades na redução do escoamento superficial, em módulos de $1,0 \mathrm{~m}^{2}$, tais como solo compactado, pavimento de concreto, paralelepípedos de granito, blocos de concreto pré-moldados intertravados, blocos de concreto com elementos vazados e concreto poroso. Os resultados obtidos neste 
experimento foram que os coeficientes de escoamento das superfícies permeáveis variaram de $0,5 \%$ para pavimento de blocos vazados, $3 \%$ para concreto poroso, entre $60 \%$ e $80 \%$ para solo compactado, de $70 \%$ a $80 \%$ para paralelepípedo de granito e blocos intertravados e $85 \%$ a 95\% para pavimento de concreto.

Para análise do uso do pavimento permeável na bacia hidrográfica, em Jaboticabal, admitiu-se a extrapolação das condiçôes e resultados do experimento de Araújo (1999) e optou-se pelo uso do pavimento permeável do tipo blocos de concretos industrializados e vazados do tipo "S", considerando aspectos de menor custo, material de construção, facilidade de instalação e, principalmente, coeficiente de escoamento de $0,5 \%$.

\section{METODOLOGIA}

\section{Área de estudo}

O município de Jaboticabal localiza-se na região nordeste do Estado de São Paulo, a uma distância de $350 \mathrm{~km}$ da capital do Estado, possui uma área de $707 \mathrm{~km}^{2}$, sendo que a área urbana ocupa $36 \mathrm{~km}^{2}$ e população de 67.300 habitantes, (IBGE, 2002). Escolheram-se para área de estudo as sub-bacias hidrográficas urbanas do bairro da Ponte Seca (SBHUPS) por apresentarem problemas históricos de inundação. As SBHUPS são compostas por 83 quadras e 1.777 lotes de tamanhos variados, como pode ser observado na Figura 3.
A avaliação do uso e ocupação do solo e o levantamento de parâmetros para implantação de medidas nos lotes foram feitos a partir de coleta de dados de aerofotogrametria, do cadastro técnico da Prefeitura Municipal de Jaboticabal, e de levantamento de campo. Para esses levantamentos e análise, adotaram-se a metodologia usada por Fontes (2000) e os resultados obtidos em Fontes (2003).

As características físicas dos lotes, tais como áreas, usos e distribuição no espaço territorial, foram relacionadas entre si, produzindo os seguintes parâmetros:

(a) Área Total do Lote (ATL): área total do lote $\left(\mathrm{m}^{2}\right)$;

(b) Área das Construções (AC): corresponde às áreas edificadas nos lotes em projeção horizontal $\left(\mathrm{m}^{2}\right)$;

(c) Área Livre (AL): correspondente à área do lote sem edificações (permeável e impermeabilizada) $\left(\mathrm{m}^{2}\right)$;

(d) Área Permeável Livre (APL): área livre do lote não impermeabilizada $\left(\mathrm{m}^{2}\right)$;

(e) Área Impermeabilizada Livre (AIL): área livre do lote que foi impermeabilizada $\left(\mathrm{m}^{2}\right)$;

(f) Área Impermeabilizada Total (AIT): somatória da área livre do lote que foi impermeabilizada $\left(\mathrm{m}^{2}\right)$ e da área de projeção das edificaçôes $\left(\mathrm{m}^{2}\right)$;

(g) Taxa de Ocupação (TO): relação entre a área construída em projeção horizontal e a área do lote (percentagem), e

(h) Taxa de Ocupação e Impermeabilização (TOI): relação entre a área construída em projeção horizontal acrescida da área impermeabilizada e A área do lote (percentagem).
As variáveis (a), (b) e (g) foram obtidas do levantamento cadastral e restituição aerofotogramétrica de 1995 fornecidos pela Prefeitura Municipal de Jaboticabal, e os dados referentes às variáveis (c), (d), (e), (f) e (h) são referentes ao levantamento de campo realizado em 2002. Dado o número de lotes (1.777) da SBHUPS, as coletas de campo foram baseadas em estudo estatístico, descrito a seguir.

Os lotes estudados foram divididos em estratos de acordo com a classe de intervalo de área total, a saber,

Estrato 01: Área menor que $160 \mathrm{~m}^{2}$;

Estrato 02: Área entre $161 \mathrm{~m}^{2}$ e 300 $\mathrm{m}^{2}$

Estrato 03: Área entre $301 \mathrm{~m}^{2}$ e 600 $\mathrm{m}^{2}$;

Estrato 04: Área entre $601 \mathrm{~m}^{2}$ e 900 $\mathrm{m}^{2}$;

Estrato 05: Área entre $901 \mathrm{~m}^{2} \mathrm{e}$ $1.200 \mathrm{~m}^{2}$;

Estrato 06: Área entre $1.201 \mathrm{~m}^{2} \mathrm{e}$ $1.500 \mathrm{~m}^{2}$;

Estrato 07: Maior que $1.501 \mathrm{~m}^{2}$, e

Estrato 08: TO igual a zero.

\section{Planejamento amostral}

O procedimento estatístico aplicado para as coletas de campo foi a amostragem estratificada aleatória proporcional (A.E.A.P.). Definiu-se o lote como elemento morfológico a ser amostrado, por ele estar presente em toda a área de estudo. A variável principal adotada para determinar o tamanho da amostra foi a Taxa de Ocupação (TO), pois está relacionada

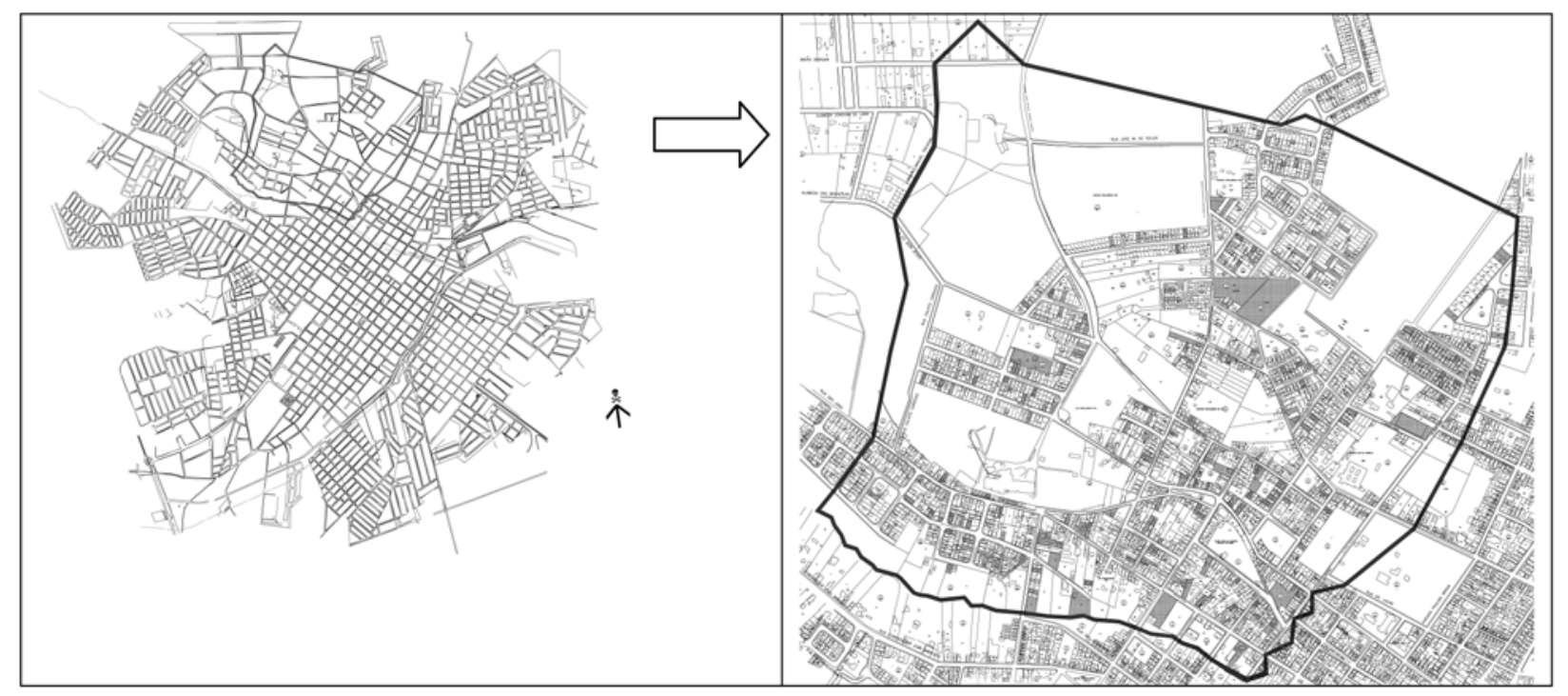

Figura 3 - Localização e detalhe da SBHUPS 
com as demais variáveis de interesse como área construída, área do lote, áreas livres, etc. Para determinar o tamanho da A.E.A.P. (n), com o número de lotes, foi usada a Equaçáo (1).

$\mathrm{n}=\left(\mathrm{N} * \sigma^{2}\right) /\left(\sigma^{2}+\left[(\mathrm{N}-1) *(\mathrm{E} / \mathrm{z})^{2}\right]\right)$

onde:

n: número de lotes visitados;

$\sigma^{2}$ : variância da variável principal - TO do lote;

$\mathrm{N}$ : tamanho da população - número total de lotes;

E: erro máximo admitido na estimativa da média, e

Z: quantil da distribuição normal correspondente a $95 \%$ de confiabilidade na estimativa da média.

A variância da $\mathrm{TO}$ para a área de estudo foi estimada a partir de dados cadastrais da Prefeitura de Jaboticabal, do ano de $1995\left(\sigma^{2}=(27,42)^{2}\right)$, e adotou-se 4\% para o erro máximo, sendo a amostra estratificada a partir do tamanho do lote.

O estrato é entendido como um subconjunto dos lotes da SBHUPS, onde o valor da área total está compreendido entre um intervalo de valores determinados. Para amostragem proporcional dos lotes para cada um dos oito estratos utilizou-se a Equação 2. A Tabela 1 apresenta a quantidade de lotes amostrados percentualmente e em valores absolutos nas colunas.

$\mathrm{n}_{\text {estrato }}=\mathrm{n} *\left(\mathrm{~N}_{\text {estrato }} / \mathrm{N}_{\text {sbhups }}\right)$

onde:

$\mathrm{n}_{\text {estrato }}$ : número de lotes por estrato para coleta de campo;

$\mathrm{N}_{\text {estrato }}$ : número total de lotes por estrato; $\mathrm{n}_{\text {bhups }}$ : número total de lotes na SBHUPS (1.777), e

n: número de amostras para coleta de campo.

Os lotes sem edificações ("vazios") na época do cadastramento urbano de 1995 correspondiam a 438 lotes do total de lotes da SBHUPS e foram separados em um estrato específico (estrato 08), independentemente da área, pois sua Taxa de Ocupação (TO) era igual a zero. Notou-se, durante o levantamento de campo, que alguns desses lotes estavam "ocupados" por edificações, totalizando quatorze lotes, que foram incorporados aos outros estratos, de acordo com a área. O número de lotes amostrados após a incorporação referida, notando-se que os lotes vagos reduziram-se de $24,39 \%$ para $15,85 \%$ do total de lotes amostrados. A seguir, serão apresentados os resultados do levantamento de campo e do cruza- mento entre as variáveis analisadas. Uma vez que os estratos 5 e 6 possuíam apenas 2 lotes amostrados cada um com características semelhantes, optou-se por agrupálos para melhorar a análise dos resultados obtidos.

\section{RESULTADOS E DISCUSSÃO}

\section{Uso e ocupação da SBHUPS}

Os lotes foram analisados por estratos, onde se verificou o comportamento das variáveis em função da área. É relevante observar que a impermeabilização foi avaliada no interior dos lotes, excluindo, portanto os arruamentos do bairro da Ponte Seca.

Observou-se que o uso do solo dos 138 lotes ocupados (164 amostrados menos 26 vagos) da SBHUPS é caracterizado por ser $97,8 \%$ residencial, $1,5 \%$ industrial e $0,7 \%$ institucional. Os estratos 1,2 e 3 e o estrato de lotes vagos (estrato 08 ) representam $92,1 \%$ do total de lotes da SBHUPS. A Tabela 2 apresenta as características médias dos estratos.

Nota-se que os lotes com áreas menores que $160 \mathrm{~m}^{2}$ apresentaram a maior taxa de impermeabilização $(97,8 \%)$ e uma ocupação de 52,5\%, em média. Com o crescimento da área do lote, observou-se redução da TO e da TOI, mas a impermeabilização do solo permaneceu significativa, com relações de (1:2) aproximadamente, indicando uma tendência de total impermeabilização de lotes pequenos.

As áreas permeáveis tendem a crescer com o aumento das áreas totais dos

Tabela I - Quantidade de lotes amostrados por estratos para levantamento de campo

Tabela I - Quantidade de lotes amostrados por estratos para
levantamento de campo

lotes, representando em média 2,0\% nos lotes menores e $74,0 \%$ nos lotes maiores.

As Figuras 4, 5 e 6 apresentam a relação dos valores médios de TO e TOI com a área do lote de todos os estratos pesquisados.

Nota-se, segundo a Figura 4, que lotes com taxas de ocupação de $55 \%$ tendem para uma total impermeabilização da área. Na SBHUPS, lotes com essas características possuem áreas inferiores a $200 \mathrm{~m}^{2}$ e taxas de impermeabilização superiores a $90 \%$, como também pode ser observado nas Figuras 5 e 6.

Esse comportamento reflete diretamente nos coeficientes de escoamento superficial da área de estudo, pois possuem um escoamento superficial direto elevado. A Figura 08 apresenta os valores médios da relação entre área total e área impermeabilizada dos lotes, na qual se observa que lotes menores tendem para uma total impermeabilização.

\section{AVALIACÃO DA IMPLAN'TACÃO DE MEDIDAS DE CONTROLE LOCAL}

Os usos de microrreservatórios de detenção (MRD) e de pavimentos permeáveis (PP) dependem, inicialmente, de fatores técnicos que possibilitem sua instalação, bem como da aceitação por parte dos moradores das SBHUPS e principalmente dos custos envolvidos.Os parâmetros considerados relevantes foram:

a) Tipo de solo;

b) Nível de água do lençol freático;

c) Profundidade da camada impermeável; 
Tabela 2 - Características médias dos lotes amostrados nas SBHUPS

\begin{tabular}{|c|c|c|c|c|c|c|c|}
\hline Estratos & $\begin{array}{c}\text { Área total } \\
\text { Lote }\left(\mathrm{m}^{2}\right) \\
1995\end{array}$ & $\begin{array}{c}\text { Área } \\
\text { construída }\left(\mathrm{m}^{2}\right) \\
1995\end{array}$ & $\begin{array}{c}\text { Área livre } \\
\text { total }\left(\mathrm{m}^{2}\right) \\
1995\end{array}$ & $\begin{array}{c}\text { Área permeável } \\
\text { total }\left(\mathrm{m}^{2}\right) \\
2002\end{array}$ & $\begin{array}{c}\text { Área impermeável } \\
\text { total }\left(\mathrm{m}^{2}\right) \\
2002\end{array}$ & $\begin{array}{c}\text { Taxa ocupação } \\
(\%) \\
(1995)\end{array}$ & $\begin{array}{c}\text { Taxa ocupação } \\
\text { impermeabilização (\%) } \\
(2002)\end{array}$ \\
\hline 1 & 140,7 & 72,6 & 68,1 & 2,9 & 137,8 & 52,5 & 97,8 \\
\hline 2 & 247,7 & 115,7 & 132,0 & 39,5 & 208,2 & 47,3 & 84,0 \\
\hline 3 & 400,2 & 149,9 & 250,3 & 98,1 & 302,1 & 38,3 & 75,9 \\
\hline 4 & 684,0 & 177,9 & 506,1 & 171,4 & 512,6 & 26,0 & 73,6 \\
\hline 5 e 6 & $1.236,7$ & 150,3 & $1.086,4$ & 705,1 & 531,6 & 12,0 & 43,8 \\
\hline 7 & $3.063,1$ & 790,2 & $2.272,9$ & $2.267,5$ & 795,6 & 25,4 & 25,8 \\
\hline
\end{tabular}

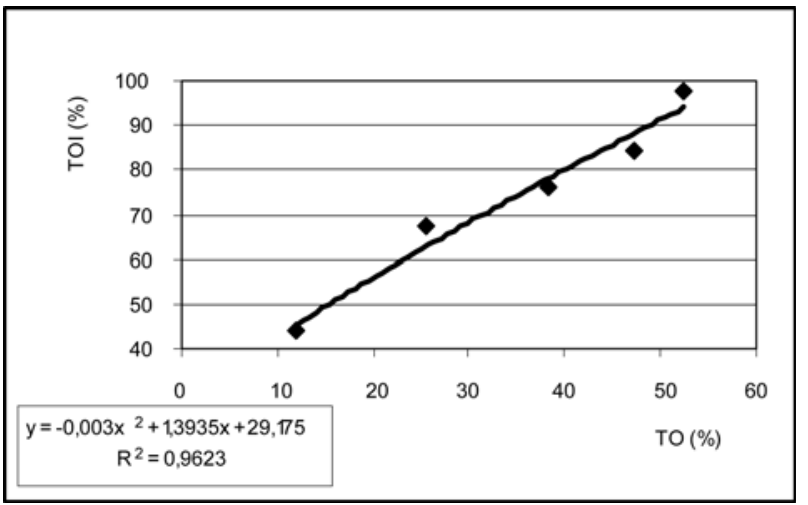

Figura 4 - Relação entre TO e TOI médias dos estratos das SBHUPS

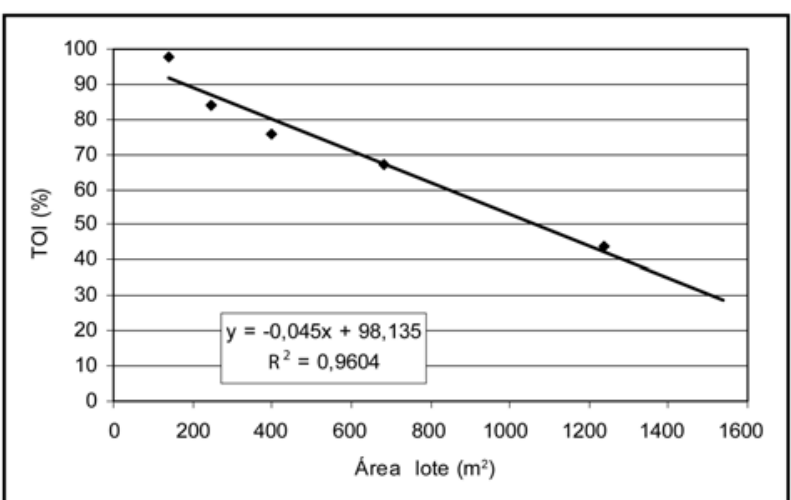

Figura 6 - Relação entre TOI média e área média do lote dos estratos das BHUPS

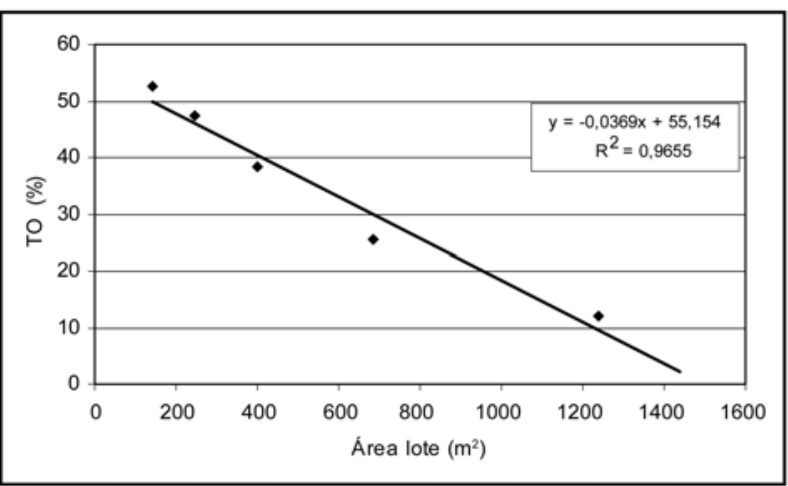

Figura 5 - Relação entre TO média e área média do lote dos estratos das SBHUPS

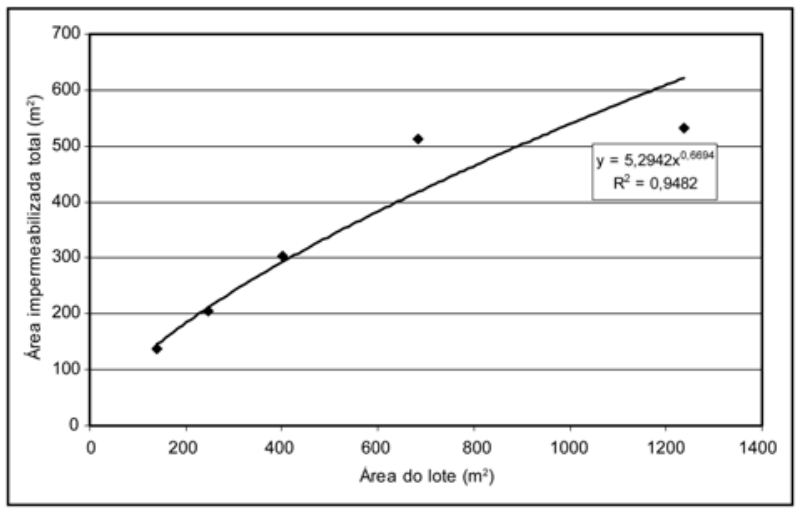

Figura 7 - Relação entre área impermeabilizada média e área média do lote dos estratos das SBHUPS d) Aceitação pelos moradores;

e) Área livre dos lotes;

f) Topografia, e

g) custos.

Inicialmente, os parâmetros tipo de solo, nível de água do lençol freático, profundidade da camada impermeável e aceitação de implantação pelos moradores foram analisados em conjunto para os dois dispositivos. $\mathrm{Na}$ seqüência, foram analisados os parâmetros área livre, topografia e custos, para cada dispositivo. $\mathrm{O}$ lote foi considerado apto para instalação das medidas de controle caso atendesse, simultaneamente, a todas as variáveis listadas acima, com exceção dos custos, uma vez que a variável custo passa por uma avaliação da capacidade de endividamento e custeio dos proprietários dos imóveis da SBHUP ou da administração municipal, aspecto que não foi abordado nesta pesquisa. As análises foram desenvolvidas, considerando a instalação dos dispositivos em lotes "ocupados", correspondendo aos estratos 1 a 7 .

\section{NÍVEL DO LENCOL FREÁTICO E DÁ CAMADA IMPERMEÁVEL}

Para analisar os parâmetros nível do lençol freático e tipo do solo, seriam necessárias as execuçôes de trabalhos de sondagem na área de estudo, fato que não foi possível devido à ausência de recursos financeiros. Como alternativa, foram utilizados trabalhos de sondagens realizados na área de estudo ou na região do município. 
Segundo o Serviço Autônomo de Água e Esgoto de Jaboticabal (1990), durante a execução do projeto do aterro sanitário, em 1990, foram executadas sondagens para a definição do nível do lençol freático.

Os valores encontrados do nível do lençol freático foram superiores a 16,4 e 23,0 metros de profundidade. A profundidade da camada impenetrável variou entre 17,0 e 27,0 metros.

Segundo depoimentos de técnicos de empresas de fundações e sondagens do município, o nível do lençol freático da região da SBHUPS varia entre 5,0 e 8,0 metros, e da camada impermeável, entre 10,0 e 15,0 metros de profundidade. Com base nestas informações, admitiu-se que os níveis do lençol freático e da camada impermeável não foram considerados fatores restritivos para a adoção das medidas de controle local estudadas neste trabalho.

\section{Tipo de solo}

A SBHUPS apresenta, na sua parte alta, a predominância do Latossolo Vermelho - Escuro - fase arenosa, e, na parte baixa, o Latossolo Roxo. Segundo Oliveira (1992), o Latossolo Vermelho Escuro "são solos bem a acentuadamente drenados, ocorrendo, porém, drenagem moderada e mesmo drenagem tendendo a imperfeita”, com características habituais de grande espessura, bom para lavoura, drenagem interna e bastante porosa, sendo comum porosidade total da ordem de $50 \%$. Os aspectos dos solos da SBHUPS favorecem a utilização de dispositivos que potencializam a infiltração, tais como pavimentos permeáveis e microrreservatórios de detenção. Estas características dos solos da área de estudo, portanto, não são restritivas para o uso das medidas de controle citadas.

\section{ACEITAÇÃO PELOS MORADORES}

A instalação das medidas de controle do escoamento nos lotes deve levar em consideração a disponibilidade do morador em aceitar sua construção no interior do lote. Para quantificar este parâmetro, foi perguntado ao morador se, "para reduzir as enchentes no bairro, estaria disposto a instalar no seu lote um dispositivo para conter a água de chuva”. Não foram explicados ao morador os custos envolvidos na construção da medida, a forma de funcionamento, a operação e a manutenção. Por isso, esse parâmetro é analisado com reserva. Mas, com a sua utilização, pode-se avaliar a sensibilidade dos moradores da SBHUPS em relação a alternativas de solução para os problemas decorrentes das inundaçōes. A aceitação média da SBHUPS foi de 82,8\%.

\section{USO DE MICRORRESERVATÓRIOS DE DETENÇÃO (MRD)}

A utilização de microrreservatórios de detenção deve observar algumas características físicas do local de implantação para garantir o seu adequado funcionamento. A seguir, apresenta-se a análise do parâmetro área levantada em campo.

\section{Análise da área livre}

Em estudos de simulação, Cruz (1998) quantificou os volumes de detenção de águas pluviais para a recuperação das características de pré-urbanização em lotes com áreas variando entre $301 \mathrm{~m}^{2}$ e $600 \mathrm{~m}^{2}$. Admitiu-se, neste trabalho, a extrapolação destas estimativas para lotes menores que $300 \mathrm{~m}^{2}$ e maiores que $600 \mathrm{~m}^{2}$, sendo que se analisou, com reserva, a extrapolação para lotes maiores que $900 \mathrm{~m}^{2}$.

A Tabela 3 apresenta os volumes de detenção estimados para os lotes amostrados, tendo como base de cálculo o valor da área média.

Para avaliar as possibilidades de instalação dos microrreservatórios de detenção, adotou-se a sua profundidade de 40 centímetros, ampliando, assim, o número de lotes aptos.

A Tabela 4 apresenta os valores de área livre necessária para instalar esse dispositivo, calculada pela divisão entre o volume de detenção estimado e a profundidade adotada. Nas colunas 4 e 5 , são apresentadas as porcentagens de lotes que possuem áreas permeáveis livres e áreas impermeabilizadas livres suficientes para a instalação do microrreservatório de detenção.

A análise da Tabela 4 mostra que o parâmetro área livre não é um quesito restritivo para a instalação de microrreservatórios de detenção nos lotes amostrados.

Tabela 3 - Volumes de detenção estimados para lotes amostrados

\begin{tabular}{ccccc}
\hline Estrato & $\begin{array}{c}\text { Área iper. } \\
\text { livre }(\%) \\
(\text { Cruz, 1998) }\end{array}$ & $\begin{array}{c}\text { TOI média } \\
(\%)\end{array}$ & $\begin{array}{c}\text { Área média } \\
(\%)\end{array}$ & $\begin{array}{c}\text { Volume de } \\
\text { detenção } \\
\text { estimado }\left(\mathrm{m}^{3}\right)\end{array}$ \\
\hline 1 & 100,0 & 97,8 & 141,0 & 0,6 \\
2 & 80,0 & 83,0 & 245,0 & 1,0 \\
3 & 75,0 & 75,7 & 382,0 & 1,3 \\
4 & 75,0 & 73,6 & 684,0 & 1,9 \\
5 e 6 & 75,0 & 43,8 & $1.237,0$ & 3,5 \\
7 & 75,0 & 25,8 & $3.063,0$ & 8,7 \\
\hline
\end{tabular}

Tabela 4 - Porcentagem de lotes amostrados com área interna livre para a instalação MRD

\begin{tabular}{cccc}
\hline Estrato & $\begin{array}{c}\text { Área livre } \\
\text { necessária } \\
\left(\mathrm{m}^{2}\right)\end{array}$ & $\begin{array}{c}\text { Lotes c/área livre } \\
\text { imperm. suficiente } \\
(\%)\end{array}$ & $\begin{array}{c}\text { Lotes c/área livre } \\
\text { permeável suficiente } \\
(\%)\end{array}$ \\
\hline 1 & 1,5 & 67,0 & 33,0 \\
2 & 2,5 & 51,5 & 48,5 \\
3 & 3,1 & 39,6 & 60,4 \\
4 & 4,9 & 0,0 & 100,0 \\
5 e 6 & 8,8 & 25,0 & 75,0 \\
7 & 21,8 & 0,0 & 100,0 \\
\hline
\end{tabular}




\section{Análise da topografia}

Esta variável não é restritiva à implantação de microrreservatórios na SBHUPS, pois o solo apresenta condiçôes favoráveis à infiltração. Os volumes armazenados não necessitariam ser escoados por gravidade para a rede de drenagem do arruamento, portanto os fundos dos microrreservatórios poderiam estar abaixo do ponto de descarga das águas pluviais na rede de drenagem do arruamento. A topografia também não seria restritiva se o volume fosse bombeado, porém essa alternativa elevaria os custos.

Apesar disto, é interessante avaliar a restrição topográfica na hipótese de o solo não apresentar boa infiltração. $\mathrm{Na}$ pesquisa de campo, consideraram-se lotes com condiçôes topográficas favoráveis à implantação aqueles com "nível acima da rua". Os lotes no "nível da rua" e "abaixo do nível da rua" teriam condiçóes desfavoráveis para o uso de microrreservatórios. A Tabela 5 mostra os percentuais de lotes por estrato que têm condiçôes favoráveis. Verifica-se, neste cenário, uma redução acentuada dos lotes até $600 \mathrm{~m}^{2}$ e um percentual ainda menor para os outros estratos, significando uma restrição severa.

Estimou-se a implantação dos microrreservatórios nos lotes que atenderam, simultaneamente, aos parâmetros: tipo de solo, nível de água do lençol freático, profundidade da camada impermeável, aceitação pelos moradores e área livre. Nota-se que a topografia deixou de ser restritiva porque o solo possui boa capacidade de infiltração. Assim, a única limitação deveu-se à aceitação de instalação pelos moradores.

A Tabela 5 mostra os lotes aptos para a instalação dos microrreservatórios de detenção por estrato, representando $82,9 \%$ dos lotes ocupados (1.239 aptos em 1.495 lotes ocupados).

\section{PAVIMENTOS PERMEÁVEIS}

Optou-se pelos blocos de concreto industrializados e vazados do tipo " $\mathrm{S}$ " e, para a análise do uso do pavimento permeável, admitiu-se a extrapolação dos resultados do experimento de Araújo (1999) e as seguintes condições: (a) declividade de $2 \%$; (b) taxa de infiltração do local superior a $7 \mathrm{~mm} / \mathrm{h}$; (c) tempo de concentração de 10 minutos; (d) período de retorno de 2 anos; (e) intensidade máxima de projeto de $94,83 \mathrm{~mm} / \mathrm{h}$; (f) pavimento permeável com sistema de infiltração total; (g) volume do reservatório de pedras igual a $0,03 \mathrm{~m}^{3}$ por metro quadrado de pavimento permeável.

\section{ÁREA LIVRE E TOPOGRAFIA}

A Tabela 6 apresenta a estimativa da área de pavimento permeável necessário por estrato, considerando as áreas médias dos lotes amostrados na SBHUPS. A área média de pavimento permeável por lote foi calculada dividindo-se o volume necessário do reservatório de pedras pela profundidade adotada de 0,15 metro.

A topografia dos lotes não necessitou ser analisada para este dispositivo de controle, pois admitiu-se que todo o volume retido fosse infiltrado dadas as boas características de infiltração do solo da área de estudo.

A Tabela 7 apresenta, na coluna 2, a área média necessária de pavimento permeável por estrato e, nas colunas 3 e 4 , o percentual de lotes com área livre suficiente e área livre insuficiente, respectiva- mente. A coluna 5 apresenta o percentual de lotes aptos, segundo o parâmetro área livre. Os estratos 1, 2 e 3 possuem uma pequena quantidade de lotes com área livre insuficiente e, nos estratos 5, 6 e 7, a área não é um quesito restritivo.

Estimou-se o número de lotes aptos para a implantação dos pavimentos permeáveis que atenderam, simultaneamente, aos parâmetros: tipo de solo, nível de água do lençol freático, profundidade da camada impermeável, aceitação pelos moradores, área livre, sendo a topografia não restritiva a este dispositivo. O número de lotes aptos é de 1.207 , representando $80,7 \%$ do total de lotes ocupados.

\section{CUSTOS DE IMPLANTACÃO MICRORREŚERVATÓRIO DE DETENÇÃO}

Estimou-se o custo envolvido na implantação dos microrreservatórios nos lotes que atenderam, simultaneamente, aos parâmetros: tipo de solo, nível de água do lençol freático, profundidade da cama-

Tabela 5 - Lotes aptos para instalação de MR por estrato e na BHUPS

\begin{tabular}{cccc}
\hline Estrato & $\begin{array}{c}\text { Condição topográfica } \\
\text { favorável }(\%)\end{array}$ & $\begin{array}{c}\text { Lotes aptos para instalação } \\
\text { de microrreservatórios } \\
(\%)\end{array}$ & (no. lotes) \\
\hline 1 & 67,0 & 88,9 & 87,0 \\
2 & 52,9 & 82,9 & 606,0 \\
3 & 51,1 & 85,1 & 433,0 \\
4 & 40,0 & 60,0 & 33,0 \\
5 e 6 & 25,0 & 60,0 & 26,0 \\
7 & 20,0 & 100,0 & 54,0 \\
Total & - & - & 1239,0 \\
\hline
\end{tabular}

Tabela 6 - Estimativa da área de pavimento permeável média por estrato

\begin{tabular}{cccc}
\hline Estrato & $\begin{array}{c}\text { Área média do lote } \\
\left(\mathrm{m}^{2}\right)\end{array}$ & $\begin{array}{c}\text { Volume do } \\
\text { reservatório de pedras } \\
\text { necessário } \\
\left.\left(0,03 \mathrm{~m}^{3} / \mathrm{m}^{2}\right){ }^{*}\right)\end{array}$ & $\begin{array}{c}\text { Área de } \\
\text { pavimento } \\
\text { permeável } \\
\left(\mathrm{m}^{2}\right)\end{array}$ \\
\hline 1 & 141,0 & 4,2 & 28,2 \\
2 & 245,0 & 7,3 & 49,0 \\
3 & 382,0 & 11,5 & 76,4 \\
4 & 684,0 & 20,5 & 136,8 \\
5 e 6 & $1.237,0$ & 37,1 & 247,4 \\
7 & $3.063,0$ & 91,9 & 612,6 \\
\hline
\end{tabular}

$\left({ }^{*}\right)$ Araújo (1999) 
da impermeável, aceitação pelos moradores, área livre e topografia favorável (cota). O número de lotes aptos é de 1.239 (82,9\%).

Optou-se por usar o microrreservatório de detenção com infiltração no solo. Os custos apresentados para microrreservatórios de detenção com volumes de até $3,0 \mathrm{~m}^{3}$ são baseados nos estudos de Cruz (1998) e, para volumes acima desse valor, os custos foram extrapolados.

A Tabela 8 apresenta uma estimativa dos custos unitários e totais da implantação do microrreservatório em 1.239 (82,9\%) dos lotes ocupados da SBHUPS. Em 693 lotes, representando 55,9\% do total de lotes aptos, poderiam ser instalados microrreservatórios de $1,0 \mathrm{~m}^{3}$, com custo global de $\mathrm{R} \$ 584.844,9$.

\section{PAVIMENTO PERMEÁVEL}

Estimou-se o custo envolvido na implantação dos pavimentos permeáveis nos lotes que atenderam, simultaneamente, aos parâmetros: tipo de solo, nível de água do lençol freático, profundidade da camada impermeável, aceitação pelos moradores, área livre e topografia favorável (cota). O número de lotes aptos é $1.207(80,7 \%)$ do total de lotes ocupados.

Avaliaram-se os custos para 1.207 lotes que atenderam a todos os parâmetros. Os parâmetros restritivos foram área livre e aceitação pelos moradores. A Tabela 9 apresenta os custos de implantação do pavimento permeável, calculado a partir da área média por lote, mostrada na Tabela 6 para os lotes aptos. Adotou-se o custo por metro quadrado igual a US\$10,1, segundo Araújo (1999).

\section{CONCLUSÕES}

Analisaram-se, neste trabalho, a ocupação e a impermeabilização dos lotes das sub-bacias urbanas da Ponte Seca, na ci- dade de Jaboticabal-SP e o uso de medidas de controle de inundação no lote, neste caso, os microrreservatórios de detenção e os pavimentos permeáveis. Destas análises, pode-se concluir que:

A taxa de ocupação e impermeabilização (TOI) média representa o grau de impermeabilização dos lotes da SBHUPS, sendo que, em lotes com áreas menores que $160 \mathrm{~m}^{2}$ (estrato 01 ), foi de $97,8 \%$, em lotes com área entre 160 e 300 (estrato 02 ), foi de $84,0 \%$ e em lotes entre 300 e 600 (estrato 03), foi de 75,9\%.

As relaçōes entre taxas de ocupação (TO) e taxas de ocupação e impermeabilização (TOI), entre TO e área dos lotes, entre TOI e áreas dos lotes, foram significativas, confirmadas pelos ajustes das equaçóes aos dados levantados, resultando em coeficientes de determinação superiores a 0,96 .

Microrreservatórios tiveram suas exigências quanto ao tipo de solo, nível de água do lençol freático, profundida-

Tabela 7 - Porcentagem de lotes amostrados com área interna suficiente para a instalação PP

\begin{tabular}{|c|c|c|c|c|c|}
\hline Estrato & $\begin{array}{l}\text { Área necessária } \\
\qquad\left(\mathrm{m}^{2}\right)\end{array}$ & $\begin{array}{c}\text { Lotes c/área } \\
\text { imperm. livre } \\
(\%)\end{array}$ & $\begin{array}{l}\text { Lotes c/área } \\
\text { livre perm. } \\
(\%)\end{array}$ & $\begin{array}{l}\text { Lotes c/área livre } \\
\text { perm. ou área } \\
\text { livre imperm. } \\
\qquad \%)\end{array}$ & $\begin{array}{c}\text { Lotes aptos } \\
(\%)\end{array}$ \\
\hline 1 & 28,2 & 88,9 & 0,0 & 88,9 & 76,0 \\
\hline 2 & 49,0 & 73,5 & 17,6 & 91,1 & 585,0 \\
\hline 3 & 76,4 & 46,8 & 53,2 & 100,0 & 433,0 \\
\hline 4 & 136,8 & 100,0 & 0,0 & 100,0 & 33,0 \\
\hline 5 e 6 & 247,4 & 100,0 & 0,0 & 100,0 & 26,0 \\
\hline \multirow[t]{2}{*}{7} & 612,6 & 100,0 & 0,0 & 100,0 & 54,0 \\
\hline & & & & Total & 1.2070 \\
\hline
\end{tabular}

Tabela 8 - Custos totais e unitários dos microrreservatórios para a SBHUPS

\begin{tabular}{ccccccc}
\hline Estrato & $\begin{array}{c}\text { V.D. }\left({ }^{* *}\right)\left(\mathrm{m}^{3}\right) \\
\text { TR 5 anos }\end{array}$ & $\begin{array}{c}\mathrm{N}^{\circ} \\
\text { lotes }(\mathrm{n})\end{array}$ & $\begin{array}{c}\text { Percentagem de } \\
\text { lotes aptos para } \\
\text { MRD }(\%)\end{array}$ & $\begin{array}{c}\text { Custo } \\
\text { lote } \\
(\mathrm{R} \$)\end{array}$ & $\begin{array}{c}\text { Custo total } \\
(\text { US\$) }\end{array}$ & $\begin{array}{c}\text { Custo total } \\
(\mathrm{mil} \mathrm{R} \$) \\
(*)\end{array}$ \\
\hline 1 & 1,0 & 87,0 & 88,9 & 843,9 & $27.396,3$ & 73,4 \\
2 & 1,0 & 606,0 & 82,9 & 843,9 & $190.829,4$ & 511,4 \\
3 & 1,5 & 433,0 & 85,1 & $1.186,7$ & $191.732,4$ & 513,8 \\
4 & 2,0 & 33,0 & 60,0 & $1.423,9$ & $17.532,9$ & 46,9 \\
5 e 6 & 4,0 & 26,0 & 60,0 & $2.317,4$ & $22.482,2$ & 60,2 \\
7 & 9,0 & 54,0 & 100,0 & $4.551,7$ & $91.713,6$ & 245,8 \\
Total & - & 1239,0 & - & - & $541.686,8$ & $1.451,7$ \\
\hline
\end{tabular}

(*) cotação do dólar R\$ 2,68 (04 - 03 - 2005)

$(* *)$ Volume de Detenção estimado 
Tabela 9 - Custos de instalação dos PPs por lote e na SBHUPS

\begin{tabular}{ccccccc}
\hline Estrato & $\begin{array}{c}\text { Área } \\
\mathrm{PP}\end{array}$ & $\begin{array}{c}\mathrm{N}^{\circ} \\
\text { lotes } \\
\left(\mathrm{m}^{2}\right)\end{array}$ & $\begin{array}{c}\text { \% de lotes } \\
\text { aptos para }\end{array}$ & $\begin{array}{c}\text { Custo } \\
\text { lote } \\
(\mathrm{RP} \$)\end{array}$ & $\begin{array}{c}\text { Custo } \\
\text { total } \\
(\mathrm{US} \$)\end{array}$ & $\begin{array}{c}\text { Custo total } \\
(\mathrm{mil} \mathrm{R} \$) \\
(*)\end{array}$ \\
\hline 1 & 28,2 & 76,0 & 77,7 & 763,3 & $21.644,8$ & 58,0 \\
2 & 49,0 & 585,0 & 79,4 & $1.326,3$ & $289.516,5$ & 775,0 \\
3 & 76,4 & 433,0 & 85,1 & $2.067,9$ & $334.102,8$ & 895,4 \\
4 & 136,8 & 33,0 & 60,0 & $3.702,7$ & $45.592,8$ & 122,2 \\
5 e 6 & 247,4 & 26,0 & 60,0 & $6.696,5$ & $64.966,2$ & 174,1 \\
7 & 612,6 & 54,0 & 100,0 & $16.581,7$ & $334.108,8$ & 895,4 \\
Total & - & 1239,0 & - & - & $1.089 .931,9$ & $2.921,0$ \\
\hline
\end{tabular}

$\left(^{*}\right)$ cotação do dólar R\$ 2,68 (04 - 03 - 2005)

de da camada impermeável, área livre para instalação atendida. A cota topográfica não foi restritiva, pois o solo oferecia condiçōes satisfatórias à infiltração. A limitação de uso foi definida pela aceitação dos moradores da instalação dos dispositivos, sendo que $82,8 \%$ deles concordam com a medida. Este dado mostra a disposição da grande maioria dos moradores e, ressalte-se, não apenas daquelas que sofrem os efeitos das inundaçōes.

Pavimentos permeáveis tiveram seu uso restringido pelos parâmetros área livre e aceitação pelos moradores. A aceitação da instalação pelos moradores é a mesma de microrreservatórios, pois não se fizeram diferenças ao questioná-los. O parâmetro área livre apresentou pequeno percentual de restriçōes. Os lotes aptos para a instalação do pavimento permeável corresponderam a 80,7 \%.

Caso o solo não apresentasse boas características de infiltração, a topografia seria um fator que limitaria a valores próximos a 50\% dos lotes aptos à instalação dos microrreservatórios e de pavimentos permeáveis.

Os custos globais para a implantação dos dispositivos nos lotes da SBHUPS, caso a Prefeitura subsidiasse integralmente a instalação dessas medidas de controle, teriam um impacto elevado no orçamento municipal e atenderia apenas a 5,6\% da área urbana.

Portanto, a definição da forma de financiamento da implantação dessas medidas de controle às inundações é fundamental, e por isso, deve estar pautada em um processo de discussão participativo, onde todos os interessados sejam envolvidos e as responsabilidades delegadas.

Espera-se, com este trabalho, ter contribuído para um melhor entendimento da ocupação e impermeabilização do solo, permitindo traçar cenários de urbanização confiáveis, estabelecer controle de inundação no lote e fora dele etc. Enfim, subsidiar o planejamento do sistema de drenagem urbana integrado com o crescimento das cidades e, com isso, espera-se que novos trabalhos introduzam outros aspectos na análise.

\section{REFERÊNCIAS}

AGRA, S, G. Estudo experimental de microrreservatórios para controle do escoamento superficial. Universidade Federal do Rio Grande do Sul, Instituto de Pesquisas Hidráulicas - Programa de Pós-Graduação em Engenharia de Recursos Hídricos e Saneamento Ambiental - Dissertação de Mestrado. www.abrh.br. Acesso em 20-02-005. 2001.

ARAÚJO, P.R. Análise experimental da eficiência dos pavimentos permeáveis na redução do escoamento superficial. Dissertação de mestrado. Universidade Federal do Rio Grande do Sul. Instituto de Pesquisas Hidráulicas. Porto Alegre-RS. 1999.

CRUZ, M. A. S. Controle do Escoamento no Lote com Detenção. Universidade Federal do Rio Grande do Sul, Instituto de Pesquisas Hidráulicas - Programa de Pós-Graduação em Engenharia de Recursos Hídricos e Saneamento Ambiental - Dissertação de Mestrado. 1998.

FONTES, A. R. M. Estudo Analítico da Morfologia Urbana no processo de urbanização visando ao planejamento de sistema de drenagem na cidade de São Carlos - São Carlos: Universidade Federal de São Carlos - Curso de PósGraduação em Engenharia Urbana - Dissertação de Mestrado. 2000.

FONTES, A.R.M.; BARBASSA, A.P. Diagnóstico e Prognóstico da Ocupação e Impermeabilização Urbanas. Revista Brasileira de Recursos Hídricos, Porto Alegre-RS, v. 8, n. 2, p. 137-147, abr/jun, 2003.

IBGE Base de Informações por Setor Censitário. CD-ROM. Rio de Janeiro. 2002.

OLIVEIRA, J.B. Classes gerais de solos doBrasil: guia auxiliar para seu reconhecimento. Jaboticabal, FUNEP. 1992.
SERVIÇO AUTÔNOMO DE ÁGUA E ESGOTO DE JABOTICABAL. Projeto executivo do aterro sanitário de Jaboticabal. SAAEJ. Jaboticabal-SP. 1990.

TASSI, R. Efeitos dos microrreservatórios de lote sobre a macrodrenagem urbana. Porto Alegre: UFRGS - Curso de Pós-Graduação em Recursos Hídricos e Saneamento Ambiental. Dissertação de Mestrado. 2002. www.abrh.br. Acesso em 20-02-2005.

\section{Endereço para correspondência:}

Lourenço Leme da Costa Junior Departamento de Engenharia Civil Programa de Pós-Graduação em Engenharia Urbana

Universidade Federal de São

Carlos

Rodovia Washington Luís (SP-3 I 0),

Km 235

I 3565-905 São Carlos - SP - Brasil

Tel.: (I6) 3995-I334

E-mail: loueng@terra.com.br 